\title{
Cardiovascular System Findings Test Code
}

National Cancer Institute

\section{Source}

National Cancer Institute. Cardiovascular System Findings Test Code. NCI Thesaurus.

Code $C 124026$.

A character or string that represents the short code name of the cardiovascular system findings assessment. 